\title{
PERCEPÇÃO DOS MORADORES SOBRE A ARBORIZAÇÃO DE RUAS DA REGIÃO CENTRAL DE MANDIRITUBA/PR
}

\author{
PERCEPTION OF THE CITIZENS ABOUT THE STREET TREES IN THE CENTRAL \\ REGION OF MANDIRITUBA/PR
}

Tatiane Lima Ho ${ }^{1}$, Bruna Kovalsyki², Kendra Zamproni ${ }^{3}$, Daniela Biondi ${ }^{4}$

\begin{abstract}
RESUMO
O estudo da percepção ambiental auxilia na compreensão das inter-relações entre o homem e o ambiente, contribuindo assim na elaboração de melhores medidas de planejamento e manutenção da arborização. Este trabalho teve como objetivo fazer um diagnóstico da percepção dos moradores sobre a arborização urbana na região central de Mandirituba - Paraná. A coleta dos dados sobre a percepção dos moradores e comerciantes locais foi pela aplicação de questionários semiestruturados. Dentre os benefícios da arborização apresentados, $54 \%$ indicaram a redução da poluição atmosférica como maior contribuição. Referente aos fatores que interferem no desenvolvimento da árvore no meio urbano, $41 \%$ apontaram o vandalismo como principal causa. Com relação a responsabilidade de manutenção da arborização, $66 \%$ dos entrevistados acreditam ser em conjunto entre moradores e prefeitura, no entanto $94 \%$ dos entrevistados mostraram-se predispostos a cuidar das árvores próximas a sua residência ou comércio. Conclui-se que a população está disposta a auxiliar no desenvolvimento e manutenção das árvores no ambiente urbano. Entretanto, sugere-se que a sensibilização dos moradores, em relação a arborização, deve ser realizada de forma contínua.
\end{abstract}

Palavras-chave: Percepção ambiental; Arborização urbana; Educação ambiental.

\section{ABSTRACT}

The environmental perception study assists in the comprehension of the interrelationships between men and environment, thus contributing in the elaboration of better planning and maintenance measures of afforestation. The main goal of this study was to do a diagnostic of the citizens' perception about the street trees in the central region of Mandirituba-Paraná. The data collection about the perception of local citizens and traders was made through questionnaires application. Among the benefits of afforestation showed, $54 \%$ indicated the atmosphere pollution reduction as the main contribution. Referent to the factors that interfere in the tree development in the urban area, $41 \%$ pointed the vandalism as principal cause. Regarding to the responsibility of the afforestation maintenance, $66 \%$ of the interviewed believe that it is a partnership between citizens and the city hall, however $94 \%$ of the interviewed showed predisposes to take care of the trees near their residences and commerce. It is possible to conclude that population is willing to assist the trees development and maintenance in the urban area. However, it is suggested that the citizens' sensitization in relation to afforestation, should be carried out continuously.

Keywords: Environmental perception, Urban forest, Environmental education.

\footnotetext{
Recebido em 29.10.2015 e aceito em 20.11.2015

1 Engenheira Florestal, Pesquisadora de Desenvolvimento Tecnológico Industrial - CNPq. Curitiba/PR. Email: tatiane.I.ho@gmail.com

2 Engenheira Florestal, Mestranda do Programa de Engenharia Florestal da Universidade Federal do Paraná. Curitiba/PR. Email: kovalsyki.b@gmail.com

3 Engenheira Florestal, Mestranda do Programa de Engenharia Florestal da Universidade Federal do Paraná. Curitiba/PR. Email: kendra.zam@gmail.com

4 Engenheira Floresta, Professora Titular do Depto. Ciências Florestais, UFPR, Bolsista de Produtividade em Pesquisa - CNPq, Curitiba/PR. Email: dbiondi@ufpr.br
} 


\section{INTRODUÇÃO}

As cidades são ecossistemas alterados pelo homem, nas quais a vegetação contribui para a redução de ruídos, amplitude térmica, poluição atmosférica e poluição visual, além de propiciar abrigo e refúgio para a fauna, auxiliar na melhoria do microclima e na identidade local (DIAS, 2006; BASSO; CORRÊA, 2014).

Martini (2015) relata que a floresta urbana é uma solução para o microclima urbano, pois contribui para o conforto térmico, uma que vez que eleva a umidade relativa e cria uma barreira contra o vento. Devido a estes benefícios, às áreas arborizadas são consideradas mais agradáveis aos sentidos humanos, se comparado a áreas desprovidas de arborização, o que faz da vegetação um elemento fundamental no planejamento dos municípios (SOUZA; CARDOSO; SILVA, 2013).

Apesar dos benefícios propiciados às cidades, a arborização urbana sofre danos, devido à falta de envolvimento da população nas fases de plantio e manutenção, como o mau planejamento (ZEM; BIONDI, 2014). O planejamento inadequado pode acarretar entupimento de encanamentos pluviais em função da biomassa vegetal depositada, dificuldade de circulação de pessoas, comprometimento do entorno quanto aos canteiros mal dimensionados e problemas na eletricidade (ROPPA et al., 2007; SILVA et al., 2015).

A análise crítica e proativa da população, a respeito da falta de planejamento urbano e dos problemas derivados do desenvolvimento, pode ser estimulada pela educação ambiental, na qual aborda a percepção do homem com o lugar vivido e a coletividade (CORRÊA; MARIN; OLIVEIRA, 2008; CORRÊA, 2008).

Por meio de estudos de percepção ambiental é possível elaborar medidas de planejamento mais apropriadas para a introdução e manutenção de árvores nas vias urbanas, como auxiliar nos processos de gestão, uma vez que pesquisas relacionadas a este tema reúnem informações e direcionam a compreensão das condições da arborização por intermédio da população (SOUZA, 2008; ZEM; BIONDI, 2014), além de propor uma reflexão das práticas já existentes e uma nova forma de defini-la no espaço (JACOBI, 2005).

Rodrigues et al. (2010) acreditam que estudos de percepção sobre a arborização urbana faz com que a população construa uma relação com a questão ambiental, podendo participar no desenvolvimento e planejamento da região. Para Corrêa (2008), a percepção ambiental pode influenciar na participação contínua da população na tomada de decisões formando uma gestão participativa.

Neste sentido, Melazo (2005) ressalta que um estudo da percepção ambiental não deve verificar apenas o entendimento do homem em relação ao ambiente, mas também uma tomada de consciência, sensibilização e compreensão do meio em sua volta. 
Diante desse contexto, este trabalho teve como objetivo obter um diagnóstico da percepção dos moradores sobre a arborização urbana nas ruas contempladas com o projeto de arborização de Mandirituba, Paraná, e sensibilizá-los frente aos benefícios, aos deveres e ao planejamento das árvores em vias públicas.

\section{MATERIAL E MÉTODOS}

O estudo foi desenvolvido no município de Mandirituba, que abrange uma área de $381,39 \mathrm{~km}^{2}$, localizada na Região Metropolitana de Curitiba, na latitude $25^{\circ} 46^{\prime} 44^{\prime \prime} \mathrm{S}$ e longitude $49^{\circ}$ 19' $34^{\prime \prime}$ W (INSTITUTO PARANAENSE DE DESENVOLVIMENTO ECONOMICO E SOCIAL - IPARDES, 2015).

A pesquisa foi realizada do dia 27 de fevereiro a 2 de março de 2012 em horário comercial e abrangeu a área central do município, contemplando os logradouros: Avenida Brasil, Rua da Liberdade, Rua Anita Muller Palu, Rua João Barbosa Mendes e Rua Lino Constantino Machado (Figura 1). Para a realização desta pesquisa, as ruas foram previamente selecionadas pela prefeitura municipal, com intuito de contempla-los no projeto de arborização urbana após esta análise. A princípio a metodologia seguiu a pesquisa por população, com a proposta de avaliar todos os estabelecimentos residenciais e comerciais localizados na área em questão.

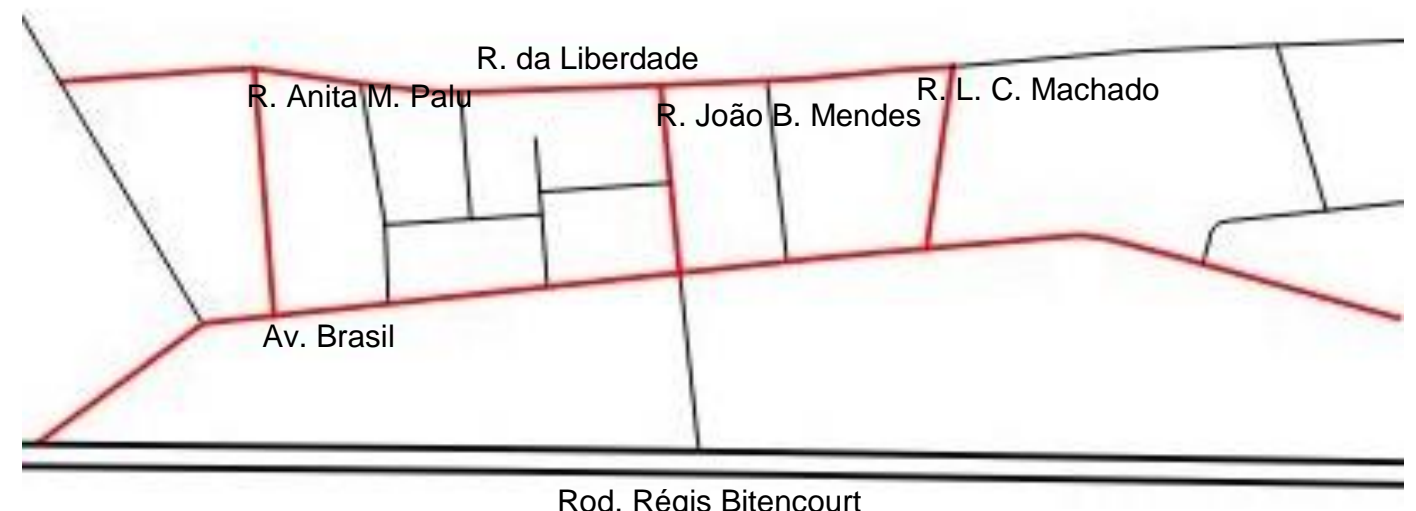

Figura 1. Mapa esquemático da área de estudo

Figure 1. Schematic map of the study area

A coleta dos dados sobre a percepção dos moradores e comerciantes locais foi realizada pelo método de educação ambiental não-formal, conforme estabelece a Política Nacional de Educação Ambiental (BRASIL, 1999), com aplicação de questionários semiestruturados contendo cinco perguntas objetiva e uma discursiva. Os questionários abrangiam as seguintes questões: a) Se os entrevistados sabiam os benefícios das árvores 
no ambiente urbano; b) Para citar a contribuição mais importante da arborização urbana; c) Quais são os fatores que impedem o bom desenvolvimento da árvore no meio urbano; d) Quem é o responsável pela árvore na frente da sua casa; e) Se a pessoa "adotaria" (no sentido de cuidar) a árvore na frente da sua casa; e f) Se você perceber que alguém está depredando uma árvore na sua rua, o que faria.

Após a aplicação dos questionários foi entregue um folder (Figura 2) a cada entrevistado, explicando algumas das questões abordadas, como forma de sensibilização dos moradores frente ao projeto de arborização dos logradouros em questão.

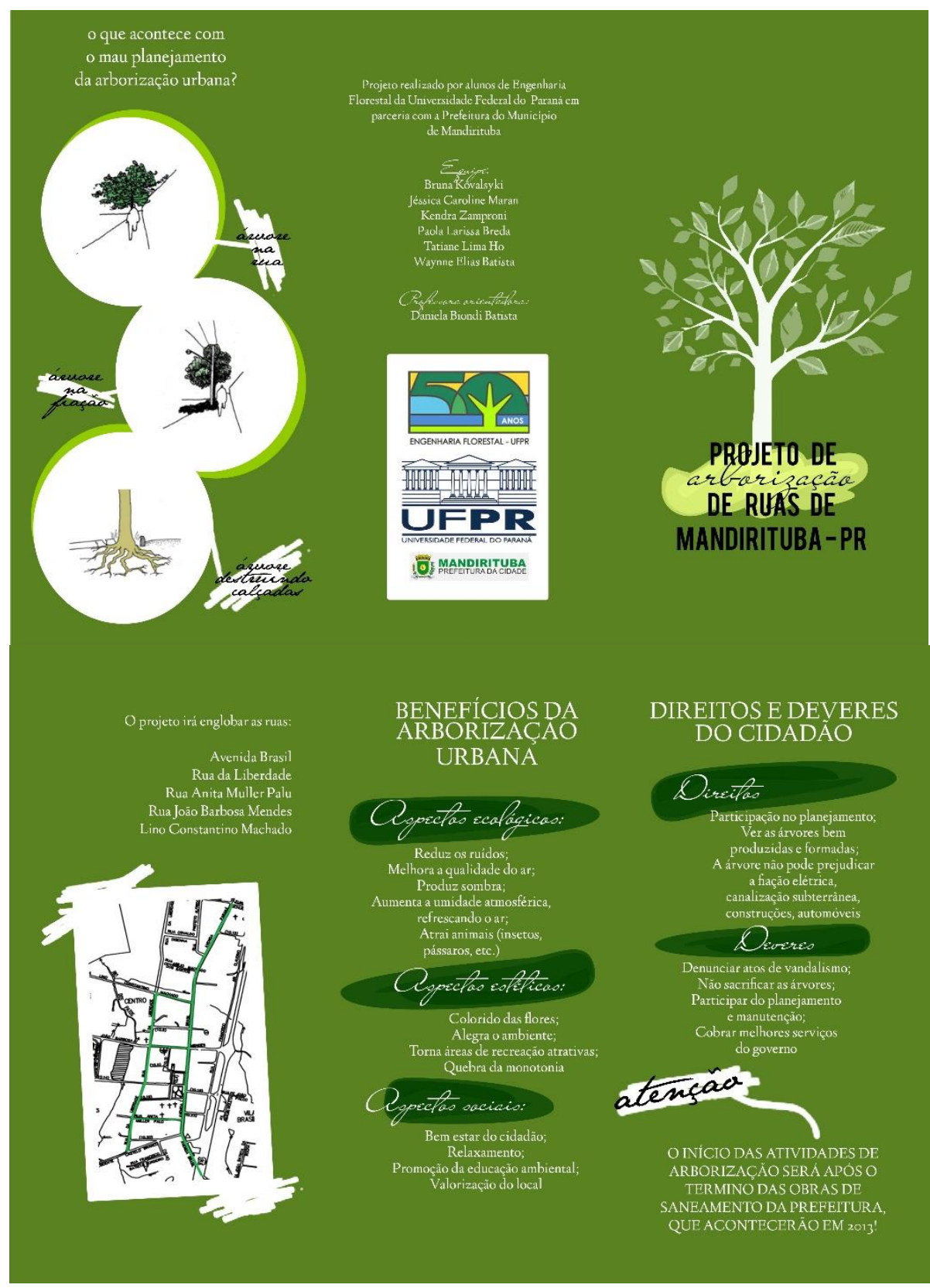

Figura 2. Folder de sensibilização ambiental

Figure 2. Environmental awareness folder 


\section{RESULTADOS E DISCUSSÃO}

Os logradouros analisados continham 176 estabelecimentos comerciais ou residenciais, dos quais 35\% participaram da pesquisa. Este percentual pode ser justificado pelo horário no qual as entrevistas foram realizadas (10 às $16 \mathrm{~h}$ ).

A partir das respostas obtidas com os questionários, pode-se observar que $73 \%$ dos entrevistados apresentaram conhecimento dos benefícios das árvores no ambiente urbano, enquanto $27 \%$ afirmaram desconhecimento quanto ao tema.

A Figura 3 apresenta as contribuições da arborização urbana apontadas pelos entrevistados.

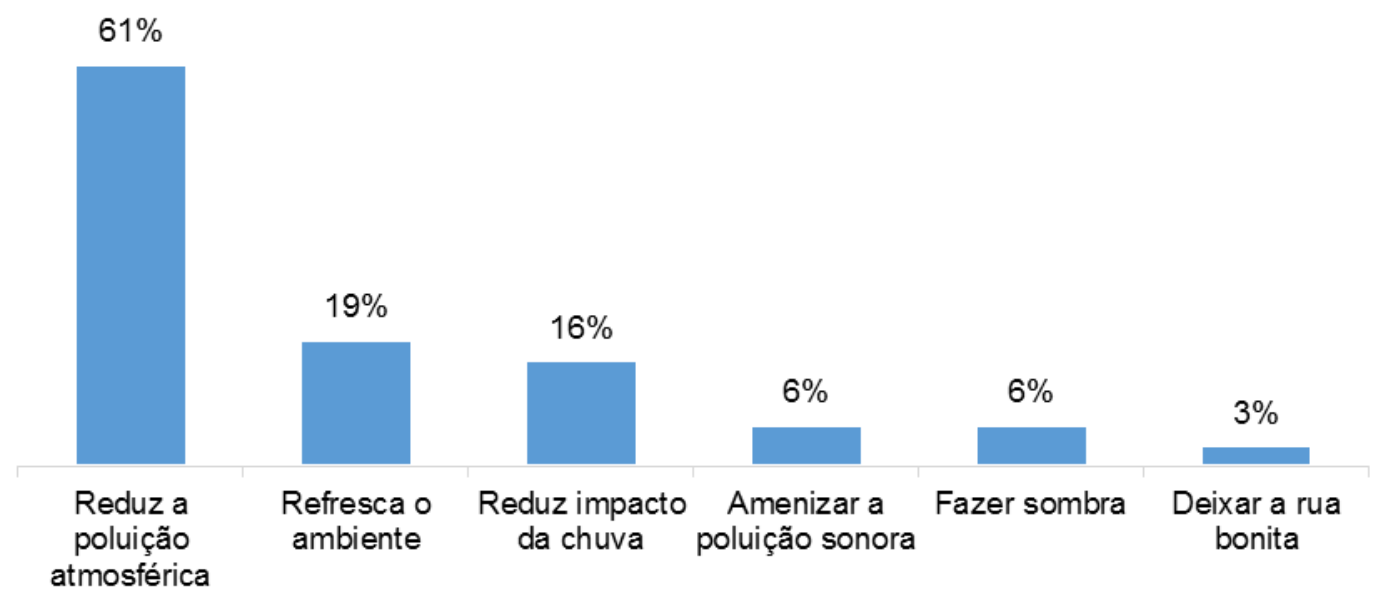

Figura 3. Contribuição da arborização urbana, de acordo com os entrevistados

Figure 3. Contribution of urban afforestation according to the interviewed

A contribuição da arborização urbana com maior porcentagem foi "reduz a poluição atmosférica" seguido de "refresca o ambiente" ou redução de calor. As duas opções mais votadas representam $80 \%$ dos entrevistados, mostrando que a percepção da maior parte dos moradores de Mandirituba está relacionada a aspectos sensitivos, de melhorar qualidade do ar e maior conforto térmico, fato que pode ter sido associado à estação do ano que a pesquisa foi realizada, verão.

O benefício "qualidade do ar" também foi evidenciado por Faria et al. (2013) como a contribuição mais importante para os moradores de Três-Rios/RJ. Rodrigues et al. (2010) verificaram que a maior contribuição da arborização era para sombreamento e redução do calor e em terceiro lugar para melhoria da qualidade do ar (14,5\% dos entrevistados). Pizziolo et al. (2014) e Lacerda et al. (2010) encontraram como principal importância a presença de sombra e redução do calor e os três benefícios mais citados em um bairro pesquisado por Souza (2008) foram: produção de sombra, purificação do ar e melhoria no clima. 
A sensação de frescor listada pela população de Mandirituba e por outros estudos é um fator perceptível, comprovado por Leal, Biondi e Batista (2014) os quais constataram que na malha urbana do município de Curitiba/PR, as menores temperaturas registradas foram obtidas em locais com concentração de remanescentes florestais ou espaços verdes públicos, quando comparados a locais com maior densidade de construção e por Barros, Musis e Hornick (2010) que verificaram a influência climática do Parque Mãe Bonifácia, Cuiabá/MT que registrou uma temperatura de $5 \stackrel{\circ}{\circ} \mathrm{C}$ na região mais interna do parque ao ser comparado com uma área mais externa do parque.

Dos fatores que impedem o bom desenvolvimento da árvore no meio urbano, a resposta mais marcada foi "vandalismo" (Figura 4).

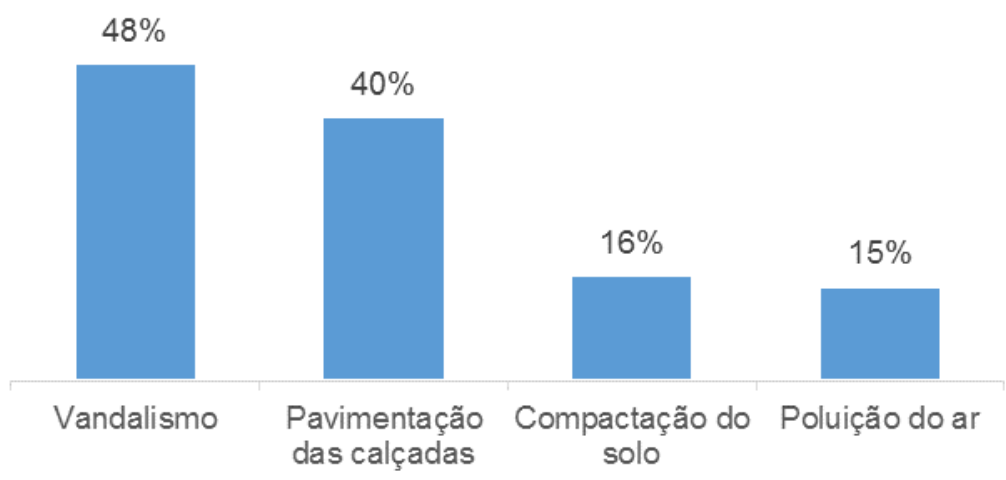

Figura 4. Fatores que impedem o bom desenvolvimento da árvore no meio urbano, de acordo com os entrevistados

Figure 4. Factors that impede the tree proper development in the urban area according to the interviewed

Biondi e Althaus (2005) acreditam que um dos problemas encontrados após o plantio das árvores nas ruas é a depredação por vandalismo, questão social que pode ser resolvida por meio da educação ambiental. $O$ ato do vandalismo está tão presente na vida das pessoas, que o fato de não danificar as árvores das vias pública é considerado por muitos uma forma de colaboração, assim como $26 \%$ dos entrevistados de Araújo, Araújo e Araújo (2010).

Referente a responsabilidade da arborização, aproximadamente $66 \%$ dos entrevistados responderam que uma árvore na frente da sua casa é responsabilidade do morador e da prefeitura, 19\% disseram que é dever do morador e $15 \%$ que é da prefeitura. Confrontando com esses dados, a maior parte dos entrevistados de Rodrigues et al. (2010), Pizziolo et al. (2014) e Silva et al. (2015), acreditam ser de responsabilidade apenas da prefeitura, já a maioria dos entrevistados por Lacerda et al. (2010), acreditam ser de responsabilidade do morador. 
O Código de Posturas do Município de Mandirituba (Lei nํ4 434, de 18 de junho de 2008) determina algumas responsabilidades da prefeitura perante a arborização:

Art. 103 A determinação das espécies de árvores que compõem a arborização de praças e vias públicas é atribuição exclusiva do órgão municipal de meio ambiente.

Art. 104 É proibido cortar, podar, derrubar ou sacrificar as árvores da arborização pública sem o consentimento expresso da Prefeitura.

Art. 120 Ficará a cargo da Prefeitura a reconstrução ou conserto de muros ou passeios afetados por alterações do nivelamento e das guias ou por estragos ocasionados pela arborização das vias públicas. (MANDIRITUBA, 2008).

Apesar da legislação definir as responsabilidades da prefeitura, vale a pena ressaltar que cabe ao cidadão cobrar e garantir que a lei seja cumprida e ter a consciência de proteger o patrimônio público.

Nesse contexto, cerca de $95 \%$ dos entrevistados disseram que gostariam de adotar a árvore em frente à sua casa ou estabelecimento, no sentido de protegê-la contra vandalismo e despender demais cuidados necessários, estabelecendo assim um ato de cidadania. Essa questão pode ser relacionada com o trabalho de Gross et al. (2012), que ao avaliar três bairros de Lages (Santa Catarina), constatou que $74,4 \%$ dos moradores colaboram com a arborização.

A Figura 5 apresenta a atitude dos entrevistados quanto ao vandalismo da arborização.

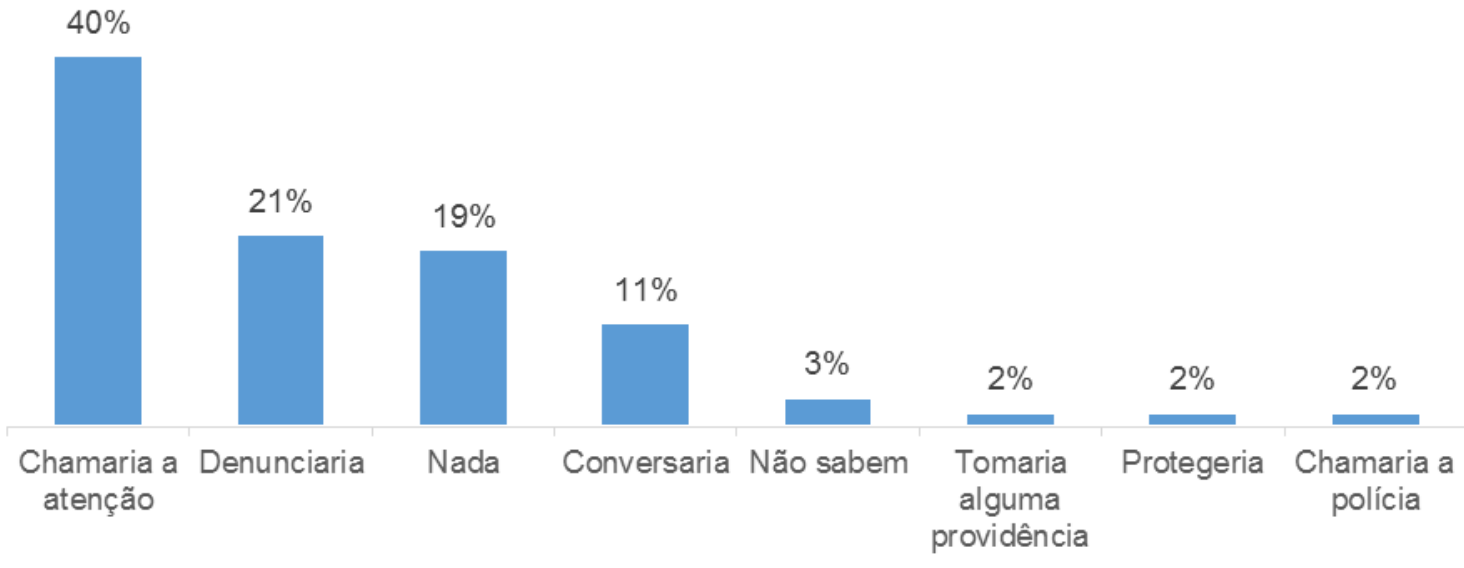

Figura 5. O que as pessoas fariam se vissem alguém depredando uma árvore na sua rua Figure 5. What people do if they saw someone depredating a tree in their street

Entre as ações da população ao ver alguém depredando uma árvore na sua rua, $40 \%$ disseram que chamaria a atenção da pessoa que cometeu essa ação, $21 \%$ denunciariam e $20 \%$ não iriam fazer nada. A ação de "não fazer nada" pode estar 
relacionada a sensação que as pessoas têm de falta de penalidade por esse tipo de atitude no meio urbano.

\section{CONCLUSÃO}

Com os resultados obtidos foi possível obter o diagnóstico da percepção dos moradores de Mandirituba em relação à arborização urbana. A maioria dos moradores tinham o conhecimento dos benefícios da arborização e citaram a redução da poluição como o mais importante.

Outros fatores importantes foram a percepção do vandalismo como prejudicial ao desenvolvimento da árvore no meio urbano e que $80 \%$ dos entrevistados tomariam alguma atitude se vissem alguém depredando uma árvore na sua rua. Essas atitudes podem estar relacionadas com as respostas de que a maioria estão dispostos a cuidar da árvore na frente da sua casa ou estabelecimento e acham que a responsabilidade da arborização é da prefeitura e do morador.

A entrega do folder didático foi uma iniciativa pontual de educação ambiental, com a finalidade de informá-los e sensibilizá-los frente aos benefícios, deveres e ao planejamento das árvores em vias públicas, mas que deve ser uma ação contínua para evitar futuros atos de vandalismo com a posterior introdução de árvores nas vias de Mandirituba.

\section{REFERÊNCIAS}

ARAÚJO, J. D. L. O.; ARAúJO, A. C.; ARAÚJO, A. C. Percepção ambiental dos residentes do bairro Presidente Médici em Campina Grande, PB, no tocante à arborização local. Revista Brasileira de Arborização Urbana, Piracicaba, v. 5, n. 2, p. 67-81, 2010.

BARROS, M. D.; MUSIS, C. R.; HORNICK, C. Parque da cidade Mãe Bonifácia, Cuiabá-MT: topofilia e amenização climática em um fragmento de cerrado urbano. Revista da Sociedade Brasileira de Arborização Urbana, Piracicaba, v. 5, n. 2, p. 01-18, 2010.

BASSO, J. M.; CORRÊA, R. S. Arborização urbana e qualificação da paisagem. Paisagem e Ambiente: Ensaios, São Paulo, n. 34, p. 129-148, 2014.

BIONDI, D; ALTHAUS, M. Árvores de rua de Curitiba - cultivo e manejo. Curitiba: FUPEF, 2005, $179 \mathrm{p}$.

BRASIL. Lei n. 9.795, de 27 de abril de 1999. Diário Oficial da União. Disponível em: <http://www.mma.gov.br/port/conama/legiabre.cfm?codlegi=321>. Acesso em: 28 out. 2015. 
CORRÊA, S. A. Percepção ambiental nos históricos de mudança de paisagem no entorno do Parque Estadual da Serra de Caldas - Caldas Novas - Goiás. $210 \mathrm{f}$. Tese (Doutorado em Ciências Ambientais) - Programa de Doutorado em Ciências Ambientais, Universidade Federal de Goiás, Goiânia, 2008.

CORRÊA, S. A. MARIN, A. A. OLIVEIRA, S. F. Trabalho e inserção no mundo da vida: significados para os desafios da educação ambiental diante do crescimento da urbanidade. Inter-ação: Revista da Faculdade de Educação da UFG, Goiânia, v. 33, n. 1, p. 71-86, 2008.

DIAS, G. F. Atividades interdisciplinares de educação ambiental. São Paulo: Global Editora e Distribuidora Ltda, 2006. 224 p.

FARIA, D. C.; DUARTE, J. M. A.; PINTO, D. M.; ALMEIDA, F. S. Arborização urbana no município de Três Rios-RJ: espécies utilizadas e a percepção de seus benefícios pela população. Revista da Sociedade Brasileira de Arborização Urbana, Piracicaba, v. 8, n. 2, p. 58-67, 2013.

GROSS; A.; DORS, P.; CAMPOS, K. A.; SILVA, A. C.; HIGUCHI, P. Percepção dos moradores e avaliação da arborização em bairros periféricos na cidade de Lages, SC. Revista da Sociedade Brasileira de Arborização Urbana, Piracicaba, v. 7, n. 2, p. 2436, 2012.

INSTITUTO PARANAENSE DE DESENVOLVIMENTO ECONOMICO E SOCIAL IPARDES. Caderno estatístico: município de Mandirituba. Disponível em: <http://www.ipardes.gov.br/cadernos/MontaCadPdf1.php?Municipio=83800>. Acesso em: 27 jul. 2015.

JACOBI, P. R. Educação ambiental: o desafio da construção de um pensamento crítico, complexo e reflexivo. Educação e Pesquisa, São Paulo, v. 31, n. 2, p. 233-250, 2005.

LACERDA, N. P.; SOUTO, P. C.; DIAS, R. S.; SOUTO, L.; SOUTO, J. Percepção dos residentes sobre a arborização da cidade de São José de Piranhas-PB. Revista da Sociedade Brasileira de Arborização Urbana, Piracicaba, v. 5, n. 4, p. 81-95, 2010.

LEAL, L.; BIONDI, D.; BATISTA, A. C. Efeitos da vegetação na variação térmica da cidade de Curitiba, PR. Floresta, Curitiba, v. 44, n. 3, p. 451-464, 2014.

MANDIRITUBA. Lei $\mathrm{n}^{\circ}$ 434, 18 de junho de 2008. Diário Oficial do Município de Mandirituba. Disponível em: <https://www.leismunicipais.com.br/codigo-de-posturasmandirituba-pr>. Acesso em: 29 jul. 2015.

MARTINI, A. A influência da floresta urbana no microclima. In: BIONDI, D. (Ed.). Floresta urbana. Curitiba: Imprensa UFPR, p. 125-152, 2015. 
MELAZO, G. C. Percepção ambiental e educação ambiental: uma reflexão sobre as relações interpessoais e ambientais no espaço urbano. Olhares \& Trilhas, Uberlândia, n. 6, p. 45-51, 2005.

PIZZIOLO, B. V.; TOSTES, R.; SILVA, K.; ARRUDA, V. M. Arborização urbana: percepção ambiental dos moradores dos bairros Bom Pastor e Centro da cidade de Ubá/MG. Revista Eletrônica em Gestão, Educação e Tecnologia Ambiental, Santa Maria, v. 18, n. 3, p. 1162-1169, 2014.

RODRIGUES, T. D.; MALAFAIA G.; QUEIROZ, S. É. E.; RODRIGUES, A. S. L. Percepção sobre arborização urbana de moradores em três áreas de Pires do Rio-Goiás. Revista de estudos ambientais, Blumenau, v. 12, n. 2, p. 47-61, 2010.

ROPPA, C.; FALKENBERG, J. R.; STANGERLIN, D. M.; BRUN, F. G. K.; BRUN, E. J.; LONGHI, S. J. Diagnóstico da percepção dos moradores sobre a arborização urbana na Vila Estação Colônia - bairro Camobi, Santa Maria - RS. Revista da Sociedade Brasileira de Arborização Urbana, Piracicaba, v. 2, n. 2, p. 11-30, 2007.

SILVA, R. V.; REGO, A. M. T.; COSTA, T. S.; SILVA, D. G.; TOSTES, R. B. Percepção ambiental dos moradores de visconde de Rio Branco-MG, em relação à arborização urbana. Revista da Sociedade Brasileira de Arborização Urbana, Piracicaba, v. 9, n. 3, p. 108-121, 2015.

SOUZA, M. D. S. Arborização urbana e percepção ambiental: uma análise descritiva em dois bairros de Natal/RN. 98 f. Dissertação (Mestrado em Geografia) - Programa de PósGraduação e Pesquisa em Geografia, Universidade Federal do Rio Grande do Norte, Natal, 2008.

SOUZA, S. M.; CARDOSO, A. L.; SILVA, A. G. Estudo da percepção da população sobre a arborização urbana, no município de Alegre-ES. Revista da Sociedade Brasileira de Arborização Urbana, Piracicaba, v. 8, n. 2, p. 68-85, 2013.

ZEM, L. M.; BIONDI, D. Análise da percepção da população em relação ao vandalismo na arborização viária de Curitiba-PR. Revista da Sociedade Brasileira de Arborização Urbana, Piracicaba, v. 9, n. 3, p. 86-107, 2014. 